\title{
Article \\ The Influence of Family Caregivers' Experience of Interprofessional Care on Their Participation in Health Checkups as Preventive Health Behavior in Japan-A Cross-Sectional Analysis
}

\author{
Gen Nakayama $^{1}\left(\mathbb{D}\right.$, Shoichi Masumoto ${ }^{2, *(D)}$, Junji Haruta ${ }^{3,4}$ and Tetsuhiro Maeno $^{4(D)}$ \\ 1 Department of Primary Care and Medical Education, Graduate School of Comprehensive Human Sciences, \\ University of Tsukuba, 1-1-1, Tennodai, Tsukuba, Ibaraki 305-8576, Japan; s1830420@s.tsukuba.ac.jp \\ 2 Department of Family Medicine, General Practice and Community Health, Faculty of Medicine, University of \\ Tsukuba, 1-1-1, Tennodai, Tsukuba, Ibaraki 305-8576, Japan \\ 3 Medical Education Center, School of Medicine, Keio University, 35, Shinano-machi, Shinjuku-ku, \\ Tokyo 160-8582, Japan; junharujp@keio.jp \\ 4 Department of Primary Care and Medical Education, Faculty of Medicine, University of Tsukuba, 1-1-1, \\ Tennodai, Tsukuba, Ibaraki 305-8576, Japan; maenote@md.tsukuba.ac.jp \\ * Correspondence: smash422@md.tsukuba.ac.jp; Tel.: +81-29-853-3189
}

\section{check for}

updates

Citation: Nakayama, G.; Masumoto, S.; Haruta, J.; Maeno, T. The Influence of Family Caregivers' Experience of Interprofessional Care on Their Participation in Health Checkups as Preventive Health Behavior in Japan-A Cross-Sectional Analysis. Int. J. Environ. Res. Public Health 2021, 18, 223. https://doi.org/10.3390/ ijerph18010223

Received: 24 November 2020 Accepted: 26 December 2020 Published: 30 December 2020

Publisher's Note: MDPI stays neutral with regard to jurisdictional clai$\mathrm{ms}$ in published maps and institutional affiliations.

Copyright: (C) 2020 by the authors. Licensee MDPI, Basel, Switzerland. This article is an open access article distributed under the terms and conditions of the Creative Commons Attribution (CC BY) license (https:// creativecommons.org/licenses/by/ $4.0 /)$.

\begin{abstract}
Background: The role of family caregivers has been vital, especially in superaging societies like Japan's. The caregivers' experience of interprofessional care is a key aspect in their evaluation of the quality of integrated care. We sought to explore whether family caregivers' experience of interprofessional care is associated with their own participation in health checkups as preventive health behaviors. Methods: We used cross-sectional data obtained during the development of the Japanese version of the Caregivers' Experience Instrument (J-IEXPAC CAREGIVERS). Participants who had provided care for at least one year were surveyed $(n=251)$. We assessed family caregivers experience of interprofessional care using J-IEXPAC CAREGIVERS and their participation in health checkups. Results: Multivariate logistic regression analysis revealed that the J-IEXPAC CAREGIVERS total score was significantly associated with the caregivers' participation in health checkups [odds ratio per 1-point increase $=1.05 ; 95 \%$ confidence interval 1.01-1.09]. Two domain scores (attention for the patient and attention for the caregiver) of J-IEXPAC CAREGIVERS were significantly associated with the outcome. Conclusions: Family caregivers with more positive experiences of interprofessional care were more likely to participate in health checkups. These results support the significance of family caregivers' experience of care, which may promote preventive health behaviors.
\end{abstract}

Keywords: caregivers; health behavior; health care quality assurance; health services evaluation; integrated care

\section{Introduction}

With a high proportion of the world population experiencing aging and an increasing incidence of chronic diseases, the role of the family caregiver has become critical. The impact of caregiving responsibilities on family caregivers' physical, psychological, and social well-being has been noted [1-3]. Family caregivers have been shown to neglect their own health and self-care and to be less likely to engage in preventive health measures $[1,2]$. The need to encourage family caregivers to take care of their own health and advise on health-promoting behaviors has been identified, as maintaining the health of the caregiver has been demonstrated to be a critical factor in enabling them to continue their provision of care [4].

When focusing on preventive health behaviors as a component of the health of family caregivers, periodic health checkups are a recommended preventive health behavior for 
family caregivers. Research experts in the fields of family caregivers' health and self-care have reported that there should be annual health checks for every caregiver [5]. The Centers for Disease Control and Prevention's web page on family caregivers claims that "encourage caregivers to get regular check-ups [6]." Although there is no standard definition of health checkups (health checks or health examinations), the Cochrane Review in 2019 defined general health checks as screening for $>1$ disease or risk factor and in $>1$ organ system and excluded screening for single diseases [7]. As this review covers trials that include cancer screening, health checkups often involve cancer screening. While the review showed that general health checks in adults aged 20 to $64 \mathrm{y}$ unselected for disease or risk factors are unlikely to reduce morbidity and mortality, it is unclear whether the results can be applied to family caregivers. Family caregivers with more than a certain number of hours of providing care have been shown to have a higher risk of cardiovascular disease than non-caregivers $[8,9]$. The benefits of health checkups among family caregivers, who are generally considered to be at risk of physically and emotionally burden [1,2], may be more meaningful than those of the general population.

In Japan, where the government recommends several types of annual health checkups depending on the subject [10], health checkups among family caregivers have also attracted attention as their preventive health behaviors. An example of an adult health checkup is an annual specific health checkup targeted at ages $40-74$ y to prevent lifestyle-related diseases, which consist of a medical consultation and examinations of items such as blood pressure, urine, and blood [10]. Any type of health checkup includes at least screening for chronic diseases such as hypertension and diabetes. Depending on the type of health checkups, the checkups may also include cancer screening (e.g., fecal occult blood testing for colorectal cancer screening). Previous observational studies in Japan have shown the effectiveness of health checkups $[11,12]$. Focusing on family caregivers, a study suggests that while female family caregivers are at higher risk of hypertension compared with non-caregivers, the caregivers have had fewer annual health checkups and therefore need some support to receive these [13]. It was also reported that a higher care-need level in care recipients was negatively associated with family caregivers' participation in health checkups [14].

A variety of individual-level and interpersonal factors influence preventive health behaviors. One of these is social support. Social support refers to the process by which interpersonal relationships promote and protect individual well-being, especially in the face of stressful living conditions [15]. Previous studies have shown that social support is positively associated with cancer screening participation [16-18]. Theoretical models indicate that social support prevents and buffers stress; increases connectedness, control and self-esteem; and consequently promotes healthy behaviors, including preventive health practices [19]. For instance, one study revealed that social support is associated with repeated breast cancer screening in low-income female caregivers [16].

Although these studies have mainly focused on social support gained from personal informal relationships, formal social support has also attracted attention when considering help for family caregivers $[20,21]$. While informal social support is provided by family members, neighbors and friends, formal social support is provided by organizations, health care and social care professionals who support patients and their family caregivers.

Efforts to assess the quality of formal support provided by such professionals have included the experience of family caregivers. Family caregiver experience has joined patient experience as a key aspect in evaluating quality of care [22]. When evaluating care for the frail and elderly and their family caregivers, the caregivers are thought to be in the best position to assess such care [23]. We previously developed a Japanese version of a scale to measure family caregiver experience of interprofessional care for patients and families [24]. This instrument was originally developed in Spain to measure the quality of integrated health and social care [25], and includes elements of professional attention to the health and well-being of family caregivers themselves. This scale can be used to assess the quality of health and social care from the caregivers' perspective. 
Given the association of social support with preventive health behavior, the quality of formal support from family caregivers' perspective (i.e., family caregivers' experience of interprofessional care) may also be related to their preventive health behavior. To our knowledge; however, the relationship between these variables has not been clarified. Researchers of patient experience are increasingly interested in understanding how patient experience is associated with other measures of clinical processes or outcomes. Such knowledge could help providers improve the efficiency and effectiveness of care [26]. Similarly, examining the relationship between family caregivers' experience and their preventive health behavior may emphasize to providers the importance of reflecting on their quality of care through the family caregivers' experience.

In this study, we aimed to explore whether family caregivers' experience of interprofessional care is associated with their participation in health checkups. We used cross-sectional data obtained during the development of the Japanese version of the scale.

\section{Materials and Methods}

\subsection{Participants and Procedures}

The cross-sectional data for this study were drawn from the development study on the Japanese version of the scale [24]. As reported in that study, recruitment for participation occurred between October and November 2019 and involved questionnaires administered for 400 family caregivers, who were caring for their community-dwelling patients under the supervision of care managers. Care managers support family caregivers and their patients by managing and coordinating the roles of other healthcare and social care professionals under Japan's long-term care insurance system.

Study participants in the development study on the Japanese version of the scale were eligible if they were "family caregivers (not receiving economic remuneration for providing care and considered related to the patient)," aged $\geq 20 \mathrm{y}$, caring for patients who were suffering from "chronic conditions" [27], caring for $\geq 6$ months, and able to read the Japanese questionnaire. "Family" was defined as "a group of individuals with a continuing legal, genetic and/or emotional relationship" [28]. A researcher instructed the care managers to request that the primary caregiver complete the questionnaire whenever possible when a patient had multiple caregivers. The participants provided informed consent via the questionnaires.

Of the 400 family caregivers recruited, 251 were included in the present study (Figure 1). Because the outcome was to ask whether family caregivers had participated in health checkups within the past year, as described below, the study excluded family caregivers who had provided care for $<1 \mathrm{y}$ and those whose length of care was missing (Figure 1). 
Family caregivers recruited in the development study

on the Japanese version of IEXPAC CAREGIVERS

$$
(n=400)
$$

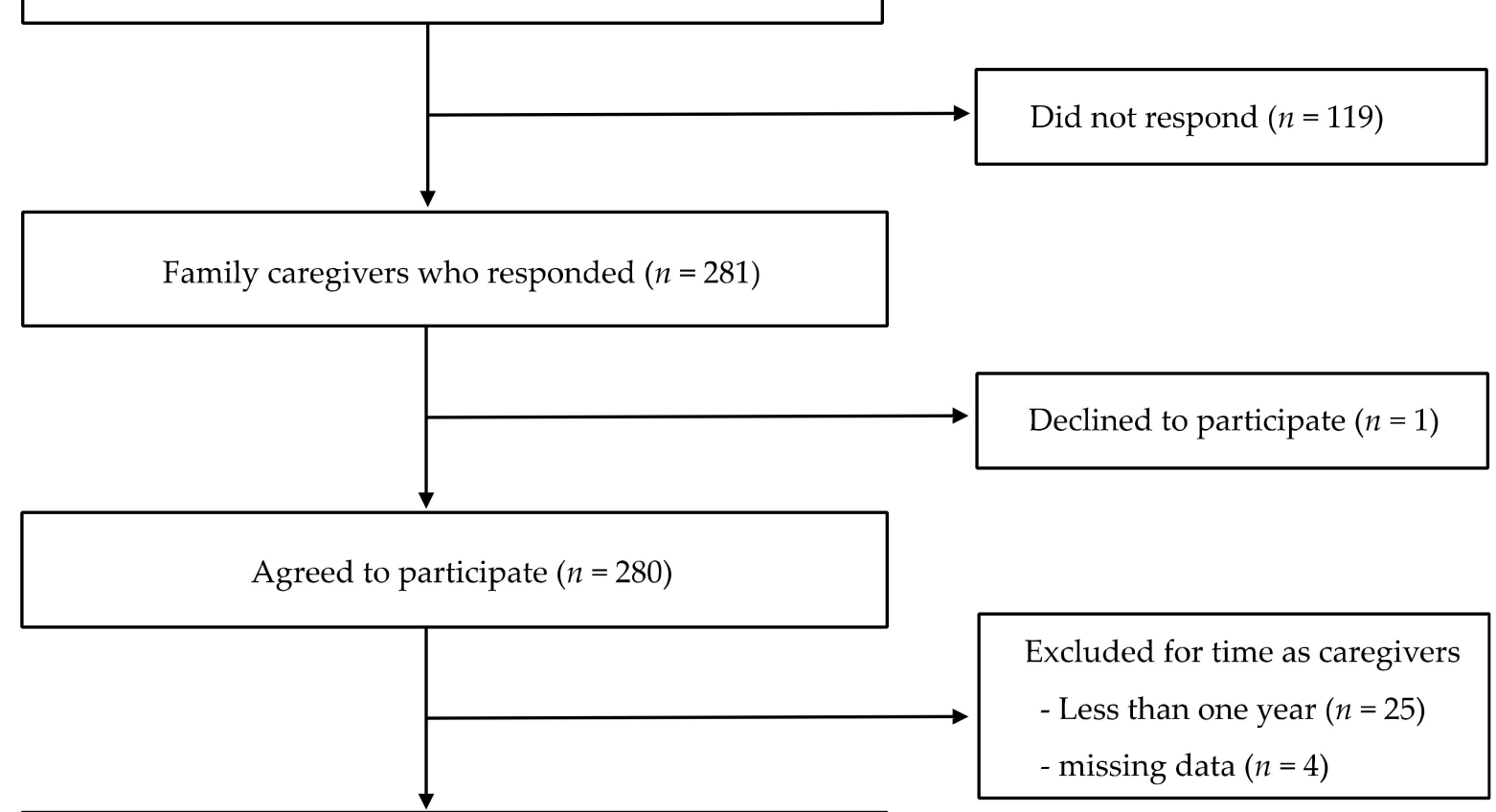

Family caregivers in analyses $(n=251)$

Figure 1. Participants flow chart.

\subsection{Outcome Variable}

The main outcome variable was whether family caregivers had undergone any health checkups in the past year. Referring to the Comprehensive Survey of Living Conditions questionnaire administered by the government [29], the number of caregivers undergoing health checkups was derived from the following question: "Have you had any health checkups (a health checkup or a thorough medical checkup) in the past year?" It excluded dental checkups or examinations as a medical practice in a hospital or clinic. In Japan, annual health checkups are mainly conducted by municipalities, employers, or insurers, and are distinct from doctor visits covered by the Japanese health insurance system. In the Comprehensive Survey of Living Conditions questionnaire, screening for cancer only is excluded from health checkups, and the questions about cancer screening are in a separate part of the questionnaire. However, because the volume of our questionnaire was limited, our questionnaire did not exclude screening for cancer only from questions about health checkups.

\subsection{Family Caregivers' Experience of Interprofessional Care}

We used the Japanese version of the Caregivers' Experience Instrument (J-IEXPAC CAREGIVERS). The Caregivers' Experience Instrument, also called IEXPAC CAREGIVERS, is a scale which measures family caregivers' experience of integrated health and social care for both patients with chronic conditions and their family caregivers [25]. This scale was developed and validated in Spain, based on the Instrument to Evaluate the EXperience of PAtients with Chronic Diseases (acronym in Spanish: IEXPAC), which is theoretically 
based on the Chronic Care Model and is inspired by patient-centered integrated care approaches [30].

J-IEXPAC CAREGIVERS is a self-reported questionnaire with 16 items: 12 items and four additional questions related to situation. This scale consists of two dimensionsattention for the patient and attention for the caregiver-according to factor analysis. For example, the former dimension consists of They respect the lifestyle of the person I care for and the latter of They are concerned about my health and wellbeing. Each item is rated on a five-point Likert scale range from 1 (Never) to 5 (Always). As items are not weighted, a scale score is calculated by simply summing the scores for each of the 12 items, but not the additional questions; the possible total score lies in the range 12-60. A high total score indicates a high quality of interprofessional care from the caregiver's perspective. We previously confirmed the validity and reliability of J-IEXPAC CAREGIVERS [24].

\subsection{Other Variables}

We identified other variables that may confound the association between family caregivers' experience of interprofessional care and their participation in health checkups based on a literature review. We included variables for age, gender, educational attainment, household equivalized income, and burden on the family caregivers, as well as care-need level of the patients. Household equivalized income was calculated as the gross income divided by square root of the number of household members; the gross income was measured in classes (e.g., 1-1.99 million JP¥) and mid-point of the class (e.g., 1.5 million JP¥) was used [31]. The equivalent income was categorized into quartiles. Caregiver burden was assessed using the short version of the Japanese version of the Zarit Caregiver Burden Interview which total score ranges from 0 to 32 (higher score means higher burden) [32]. The caregiver burden scale suggests that caregivers are at risk of depression if they score 13 or more [33]. The care-need level was classified as "support required" (2 levels) or "care required" (5 levels) according to Japan's long-term care insurance system [34]. Based on a previous study, we apportioned the care-need level into three categories: lower need level (support required levels 1 and 2), middle need level (care required levels 1-3) and higher need level (care required levels 4 and 5) [14]. We defined gender, educational attainment, household equivalized income, and care-need level as categorical variables.

\subsection{Statistical Analysis}

Descriptive statistics were obtained for participants' characteristics. Unadjusted associations between participants' characteristics and the outcome measure were analyzed using the chi-squared test for categorical variables and the Mann-Whitney test for continuous variables. An unadjusted association between the total score for J-IEXPAC CAREGIVERS and the outcome was analyzed using the independent samples $t$-test. In these analyses, missing values were treated by pairwise exclusion.

We used multivariate logistic regression analysis to determine whether the total score for J-IEXPAC CAREGIVERS was positively associated with participation in health checkups. The following possible confounders were included in the analysis: age, gender, educational attainment, household equivalized income and burden of the family caregivers; care-need level of the patients. To examine the multi-collinearity of the independent variables, we analyzed Spearman's rank correlation coefficient and checked variance inflation factors using multiple regression analysis. In addition, we also performed exploratory analyses of participation in health checkups in relation to J-IEXPAC CAREGIVERS domain scores (attention for the patient and attention for the caregiver) using the same model as the primary analysis. In the exploratory analyses, we repeated the comparisons without the Bonferroni correction.

In the verification of the sample size in the logistic regression analysis, events per variable values of $\geq 10$ were necessary [35]. In this study, with seven independent variables, about 250 samples were needed. Therefore, in the logistic regression analysis, we accounted for missing data for independent variables by using multiple imputation with a fully 
conditional specification. We used the method at each item level (not at the scale level) for the score of J-IEXPAC CAREGIVERS. Statistical analyses were conducted using SPSS Statistics version 26 (IBM Corp, Armonk, NY, USA).

\subsection{Ethical Considerations}

The study was approved by the Ethics Committee of the Faculty of Medicine, University of Tsukuba (No. 1417-1). All participants were volunteers and checked the box on the questionnaire indicating their intention to participate.

\section{Results}

Table 1 shows the distribution of the 251 participants' characteristics. The majority of family caregivers were women $(77.7 \%)$, aged $\geq 58$ y $(75.3 \%)$, with less than a college education $(58.6 \%)$ and scored $<13$ points on the short version of the Japanese version of the Zarit Caregiver Burden Interview (61.9\%). The majority of patients had middle care-need level (care required level 1-3) (61.8\%). Although not shown in the table, the following primary health conditions were the most common among patients: neurological disorders including dementia (25.9\%), stroke (21.9\%) and joints/spinal cord/bone fracture (17.1\%). The overall proportion of family caregivers who had participated in health checkups in the past year was $72.5 \%$.

Table 1. Participant characteristics by caregiver participation in health checkups in the past year.

\begin{tabular}{|c|c|c|c|c|c|c|c|}
\hline \multirow[t]{2}{*}{ Characteristic } & \multirow{2}{*}{\multicolumn{2}{|c|}{$\begin{array}{c}\text { Total } \\
(n=251)\end{array}$}} & \multicolumn{5}{|c|}{ Participation in Health Checkups } \\
\hline & & & Yes & $=182)$ & & $=69)$ & $p$ Value \\
\hline \multicolumn{8}{|l|}{ Gender } \\
\hline Men & 56 & $(22.3 \%)$ & 41 & $(22.5 \%)$ & 15 & $(21.7 \%)$ & 0.893 \\
\hline Women & 195 & $(77.7 \%)$ & 141 & $(77.5 \%)$ & 54 & $(78.3 \%)$ & \\
\hline Data missing & 0 & & & & & & \\
\hline \multicolumn{8}{|l|}{ Education } \\
\hline Less than high school & 21 & $(8.4 \%)$ & 10 & $(5.5 \%)$ & 11 & $(15.9 \%)$ & 0.019 \\
\hline High school & 126 & $(50.2 \%)$ & 90 & $(50.0 \%)$ & 36 & $(52.2 \%)$ & \\
\hline Junior college or vocational college & 61 & $(24.3 \%)$ & 46 & $(25.6 \%)$ & 15 & $(21.7 \%)$ & \\
\hline College or graduate school & 40 & $(15.9 \%)$ & 34 & $(18.9 \%)$ & 6 & $(8.7 \%)$ & \\
\hline Data missing & 3 & & & & & & \\
\hline \multicolumn{8}{|l|}{ Equivalent income (million Japanese yen) } \\
\hline Q1 $(<1.06)$ & 62 & $(24.7 \%)$ & 30 & $(16.5 \%)$ & 32 & $(46.4 \%)$ & $<0.001$ \\
\hline Q2 (1.06-2.01) & 59 & $(23.5 \%)$ & 43 & $(23.6 \%)$ & 16 & $(23.2 \%)$ & \\
\hline Q3 (2.02-3.16) & 56 & $(22.3 \%)$ & 41 & $(22.5 \%)$ & 15 & $(21.7 \%)$ & \\
\hline $\mathrm{Q} 4(\geq 3.17)$ & 66 & $(26.3 \%)$ & 61 & $(33.5 \%)$ & 5 & $(7.2 \%)$ & \\
\hline Data missing & 8 & & & & & & \\
\hline \multicolumn{8}{|l|}{ Patients } \\
\hline \multicolumn{8}{|l|}{ Care-need level } \\
\hline Lower (support required 1 and 2) & 36 & $(14.3 \%)$ & 25 & $(13.7 \%)$ & 11 & $(15.9 \%)$ & 0.277 \\
\hline Middle (care required 1-3) & 155 & $(61.8 \%)$ & 118 & $(64.8 \%)$ & 37 & $(53.6 \%)$ & \\
\hline Higher (care required 4 and 5) & 55 & $(21.9 \%)$ & 36 & $(19.8 \%)$ & 19 & $(27.5 \%)$ & \\
\hline Data missing & 5 & & & & & & \\
\hline Caregivers & & & $\mathrm{Me}$ & n (IQR) & & & \\
\hline Age (years, $n=251$ ) & 64 & $(58-70)$ & 63 & $(58-69)$ & 66 & $(57-72.5)$ & 0.078 \\
\hline Caregiver burden score (points, $n=247$ ) & 11 & $(6-17)$ & 11 & $(6-16)$ & 10.5 & $(5-18)$ & 0.834 \\
\hline
\end{tabular}

$\mathrm{Q}$, Quartile. IQR, interquartile range. Comparisons of proportions were made using chi-square test. Comparisons of medians were made using the Mann-Whitney test.

Table 2 shows the mean and standard deviation of the J-IEXPAC CAREGIVERS scores overall and by caregiver participation in health checkups. The average J-IEXPAC CAREGIVERS total score was 40.5 out of 60 points. The J-IEXPAC CAREGIVERS total score was significantly associated with family caregivers' participation in health checkups. 
The univariate associations between the J-IEXPAC CAREGIVERS domain scores and the outcome were also significant.

Table 2. Distribution ${ }^{1}$ of J-IEXPAC CAREGIVERS and unadjusted associations with caregiver participation in health checkups.

\begin{tabular}{|c|c|c|c|c|c|}
\hline & \multirow[b]{2}{*}{ Total $(n=234)$} & \multicolumn{2}{|c|}{$\begin{array}{c}\text { Family Caregiver Participation in } \\
\text { Health Checkups }\end{array}$} & \multirow[t]{2}{*}{$95 \% \mathrm{CI}$} & \multirow[t]{2}{*}{$p$} \\
\hline & & Yes $(n=170)$ & No $(n=64)$ & & \\
\hline \multirow[t]{2}{*}{$\begin{array}{l}\text { J-IEXPAC CAREGIVERS } \\
\text { Total score }^{2}\end{array}$} & $40.5(8.8)$ & $41.3(8.5)$ & $38.4(9.1)$ & $0.4-5.4$ & 0.025 \\
\hline & Total $(n=241)$ & Yes $(n=175)$ & No $(n=66)$ & & \\
\hline \multirow[t]{2}{*}{$\begin{array}{c}\text { Domain score } \\
\text { Attention for the patient }{ }^{3}\end{array}$} & $25.6(5.3)$ & $26.1(5.1)$ & $24.3(5.6)$ & $0.3-3.3$ & 0.019 \\
\hline & Total $(n=247)$ & Yes $(n=179)$ & No $(n=68)$ & & \\
\hline $\begin{array}{l}\text { Domain score } \\
\text { Attention for the caregiver } 4\end{array}$ & $12.9(3.3)$ & $13.2(3.3)$ & $12.2(3.3)$ & $0.1-2.0$ & 0.032 \\
\hline
\end{tabular}

${ }^{1}$ Mean (SD). ${ }^{2}$ Possible score lies in the range 12-60. ${ }^{3}$ Possible score lies in the range 7-35. ${ }^{4}$ possible score lies in the range 4-20. Independent samples $t$-test.

Table 3 shows the results of multivariate logistic regression analysis investigating the associations of the J-IEXPAC CAREGIVERS total score with family caregivers' participation in health checkups. After adjustment for possible confounders, the J-IEXPAC CAREGIVERS total score was significantly associated with family caregivers' participation in health checkups (odds ratio (OR) per 1-point increase $=1.05 ; 95 \%$ confidence interval (CI) 1.01-1.09). The coefficient of correlation among all the independent variables was $<0.5$ and all variance inflation factors were $\leq 1.3$, indicating there was no problem with multi-collinearity.

Table 3. Associations of the J-IEXPAC CAREGIVERS total score and other variables with caregiver participation in health checkups $(n=251)$.

\begin{tabular}{|c|c|c|c|}
\hline & OR & $(95 \% \mathrm{CI})$ & $p$ Value \\
\hline J-IEXPAC CAREGIVERS total score ${ }^{1}$ & 1.05 & $(1.01-1.09)$ & 0.013 \\
\hline \multicolumn{4}{|l|}{ Gender } \\
\hline Men & \multicolumn{2}{|c|}{ Reference } & \\
\hline Women & 1.07 & $(0.49-2.35)$ & 0.864 \\
\hline Age (years) & 1.01 & $(0.97-1.05)$ & 0.683 \\
\hline \multicolumn{4}{|l|}{ Education } \\
\hline Less than high school & \multicolumn{2}{|c|}{ Reference } & \\
\hline High school & 1.63 & $(0.58-4.57)$ & 0.357 \\
\hline Junior college or vocational college & 1.19 & $(0.35-4.04)$ & 0.785 \\
\hline College or graduate school & 2.35 & $(0.60-9.87)$ & 0.244 \\
\hline \multicolumn{4}{|l|}{ Equivalent income (million Japanese yen) } \\
\hline Q1 $(<1.06)$ & \multicolumn{2}{|c|}{ Reference } & \\
\hline Q2 (1.06-2.01) & 2.54 & $(1.12-5.74)$ & 0.026 \\
\hline Q3 (2.02-3.16) & 2.76 & $(1.21-6.32)$ & 0.016 \\
\hline $\mathrm{Q} 4(\geq 3.17)$ & 15.21 & $(4.71-49.15)$ & $<0.001$ \\
\hline Caregiver burden score ${ }^{1}$ & 0.99 & $(0.95-1.04)$ & 0.732 \\
\hline \multicolumn{4}{|l|}{ Care-need level } \\
\hline Lower (support required 1 and 2) & \multicolumn{2}{|c|}{ Reference } & \\
\hline Middle (care required 1-3) & 1.41 & $(0.57-3.51)$ & 0.457 \\
\hline Higher (care required 4 and 5) & 0.59 & $(0.21-1.66)$ & 0.317 \\
\hline
\end{tabular}

\footnotetext{
${ }^{1}$ per 1-point increase. OR, odds ratio. Q, Quartile.
} 
Table 4 shows the results of multivariate logistic regression analysis investigating the associations of the J-IEXPAC CAREGIVERS domain scores with family caregivers participation in health checkups. The domain scores were also positively associated with family caregivers' participation in health checkups: attention for the patient (OR per 1point increase $=1.08 ; 95 \%$ CI 1.01-1.15), and attention for the caregiver (OR per 1-point increase $=1.12 ; 95 \%$ CI 1.02-1.24).

Table 4. Associations of two domain scores of J-IEXPAC CAREGIVERS and other variables with caregiver participation in health checkups $(n=251)$.

\begin{tabular}{|c|c|c|c|}
\hline & OR & $(95 \% \mathrm{CI})$ & $p$ Value \\
\hline Attention for the patient ${ }^{1}$ & 1.08 & $(1.01-1.15)$ & 0.016 \\
\hline Gender & & & \\
\hline Men & \multicolumn{2}{|c|}{ Reference } & \\
\hline Women & 1.07 & $(0.49-2.33)$ & 0.874 \\
\hline Age (years) & 1.01 & $(0.97-1.05)$ & 0.662 \\
\hline Education & \multirow{2}{*}{\multicolumn{2}{|c|}{ Reference }} & \\
\hline Less than high school & & & \\
\hline High school & 1.58 & $(0.56-4.45)$ & 0.386 \\
\hline Junior college or vocational college & 1.13 & $(0.33-3.84)$ & 0.847 \\
\hline College or graduate school & 2.10 & $(0.50-8.77)$ & 0.313 \\
\hline \multicolumn{4}{|l|}{ Equivalent income (million Japanese yen) } \\
\hline Q1 $(<1.06)$ & \multicolumn{2}{|c|}{ Reference } & \\
\hline Q2 (1.06-2.01) & 2.61 & $(1.15-5.92)$ & 0.026 \\
\hline Q3 (2.02-3.16) & 2.91 & $(1.27-6.64)$ & 0.016 \\
\hline $\mathrm{Q} 4(\geq 3.17)$ & 15.50 & $(4.79-49.99)$ & $<0.001$ \\
\hline Caregiver burden score ${ }^{1}$ & 0.99 & $(0.95-1.04)$ & 0.723 \\
\hline \multicolumn{4}{|l|}{ Care-need level } \\
\hline Lower (support required 1 and 2) & \multicolumn{2}{|c|}{ Reference } & \\
\hline Middle (care required 1-3) & 1.40 & $(0.56-3.46)$ & 0.470 \\
\hline Higher (care required 4 and 5) & 0.58 & $(0.21-1.64)$ & 0.307 \\
\hline Attention for the caregiver ${ }^{1}$ & 1.12 & $(1.02-1.24)$ & 0.023 \\
\hline \multicolumn{4}{|l|}{$\begin{array}{l}\text { Attention for the caregiver }{ }^{1} \\
\text { Gender }\end{array}$} \\
\hline Men & \multicolumn{2}{|c|}{ Reference } & \\
\hline Women & 1.10 & $(0.50-2.40)$ & 0.819 \\
\hline & 1.01 & $(0.97-1.05)$ & 0.708 \\
\hline \multicolumn{4}{|l|}{ Education } \\
\hline Less than high school & \multicolumn{2}{|c|}{ Reference } & \\
\hline High school & 1.68 & $(0.60-4.73)$ & 0.323 \\
\hline Junior college or vocational college & 1.20 & $(0.35-4.11)$ & 0.768 \\
\hline College or graduate school & 2.60 & $(0.61-10.98)$ & 0.195 \\
\hline \multicolumn{4}{|l|}{ Equivalent income (million Japanese yen) } \\
\hline Q1 $(<1.06)$ & \multicolumn{2}{|c|}{ Reference } & \\
\hline Q2 (1.06-2.01) & 2.51 & $(1.11-5.67)$ & 0.026 \\
\hline Q3 (2.02-3.16) & 2.64 & $(1.15-6.06)$ & 0.016 \\
\hline $\mathrm{Q} 4(\geq 3.17)$ & 15.01 & $(4.66-48.36)$ & $<0.001$ \\
\hline Caregiver burden score $^{1}$ & 0.99 & $(0.95-1.04)$ & 0.731 \\
\hline \multicolumn{4}{|l|}{ Care-need level } \\
\hline Lower (support required 1 and 2) & \multicolumn{2}{|c|}{ Reference } & \\
\hline Middle (care required 1-3) & 1.39 & $(0.56-3.45)$ & 0.473 \\
\hline Higher (care required 4 and 5 ) & 0.61 & $(0.22-1.70)$ & 0.344 \\
\hline
\end{tabular}

${ }^{1}$ per 1-point increase. OR, odds ratio. Q, Quartile.

\section{Discussion}

Our results showed that family caregivers' experience of interprofessional care for patients and the caregivers was positively associated with the caregivers' participation in health checkups. This association persisted after adjustment for possible confounders. In addition, two domains of J-IEXPAC CAREGIVERS, which reflects attention for the 
patient and attention for the caregiver, were associated with the caregivers' participation in health checkups. Our study indicated the significance of family caregivers' experience of interprofessional care in the context of their preventive health behaviors.

Considering that family caregivers' experience of interprofessional care reflects one aspect of the quality of social support, especially formal support provided by healthcare and social care professionals, the results of this study are consistent with those of previous studies that have examined the association between social support and disease screening participation [16-18] or health behavior in family caregivers [36]. Messina and Lane et al. showed that emotional/informational support, a component of social support, is associated with repeated breast cancer screening in low-income female caregivers [16]. They measured emotional/informational support as reflecting the availability of someone to share expressions of positive affect, offer empathetic understanding, encourage one to express feelings, and offer advice, information, guidance, or feedback. The key components of J-IEXPAC CAREGIVERS include professional support to improve family caregivers' own health and well-being and self-management skills in caregiving, which can be termed emotional/informational support. These may explain the significant association between J-IEXPAC CAREGIVERS and the family caregivers' participation in health checkups.

Focusing on social support among family caregivers, as Messina and Lane et al., noted, peer group participation is a key element in improving social support in cases in which existing social network members do not provide the necessary support. The introduction of a new network of individuals experiencing similar stressors enhances emotional/informational support and may promote preventive health behaviors [16]. JIEXPAC CAREGIVERS includes an item to assess whether professionals encourage family caregivers to participate in peer groups. Thus, family caregivers with high J-IEXPAC CAREGIVERS scores may be encouraged to participate in informal peer groups with formal support from professionals, thereby enhancing their emotional/informational support and contributing to the promotion of preventive health behaviors, i.e., their participation in health checkups.

Although these possible mechanisms account for the attention for the caregiver domain in J-IEXPAC CAREGIVERS, it is interesting that the results of this study also show a significant association between attention for the patient and caregivers' participation in health checkups. This may be due to the strong relationship between the two domain scores [24]. Caregivers may devote years of their own lives to caring for a loved one with chronic illness, and the needs and interdependence of the patient and family increase as the family ages. Professionals are required to provide comprehensive care for patients and their family caregivers [37]. In this study, interprofessional care for both patient and family caregiver (not just for the patient or the family caregiver) and the caregiver's perception of this, may have contributed to the caregiver's preventive health behavior.

To our knowledge, this study is the first to reveal an association between family caregivers' experience of interprofessional care and their preventive health behaviors. The IEXPAC CAREGIVERS is an established measure for the evaluation of family caregivers' experience of health and social care in Spain and Japan, and represents the quality of integrated care for both patient and caregiver. The findings of this study may underscore the clinical significance of evaluating the quality of care in terms of the family caregivers' experience. Family caregivers may be able to stay healthy and continue to care longer [4] when they feel that professionals provide integrated health and social care.

Our study has several potential limitations. First, there are some potential unmeasured confounders: self-rated health, which is often used as a confounder in testing preventive health behaviors; informal social support variables, including the presence of multiple family caregivers; working; routine visit to hospitals and/or clinics; patient experience (the quality of primary care that caregivers experience as patients), which has been demonstrated to be linked to clinical process of preventive care [38,39]. Before a variable can be considered a potential confounder, it must be shown to be associated with the exposure [40]. Similarly, to determine whether these present variables can be considered confounders, we 
need to examine associations between them and J-IEXPAC CAREGIVES in future studies. Second, the study participants may not be representative of Japanese family caregivers. Family caregivers who were interested in evaluating the quality of care might have been more likely to complete the questionnaires. Third, the data were cross-sectional, and a causal relationship between family caregiver experience of interprofessional care and participation in health checkups cannot be definitively established.

\section{Conclusions}

We found that better family caregiver experience of interprofessional care for patients and caregivers was associated with caregiver participation in health checkups. These results support the significance of family caregiver experience of care, which may promote preventive health behaviors, such as participation in health checkups.

Author Contributions: Conceptualization, G.N., S.M. and J.H.; methodology, G.N., S.M. and J.H.; software, G.N.; validation, G.N., S.M. and J.H; formal analysis, G.N.; investigation, G.N.; resources, G.N.; data curation, G.N.; writing—original draft preparation, G.N.; writing—review and editing, G.N., S.M., J.H. and T.M.; visualization, G.N.; supervision, S.M., J.H. and T.M; project administration, S.M.; funding acquisition, G.N. All authors have read and agreed to the published version of the manuscript.

Funding: The cross-sectional data for this study were drawn from the development research project of the Japanese version of the Caregivers' Experience Instrument (J-IEXPAC CAREGIVERS), which is supported by grant-in-aid from Japan Primary Care Association.

Institutional Review Board Statement: The study was conducted according to the guidelines of the Declaration of Helsinki, and approved by the Ethics Committee of the Faculty of Medicine, University of Tsukuba (protocol code 1417-1 and date of approval October 8, 2019).

Informed Consent Statement: Informed consent was obtained from all subjects involved in the study.

Data Availability Statement: The data presented in this study are available on request from the corresponding author. The data are not publicly available due to ethical considerations.

Acknowledgments: The authors thank everyone involved in the study. We are very grateful to Mercedes Guilabert Mora, who is the IEXPAC CAREGIVERS scale's developer. We thank Libby Cone, MD, MA, from DMC Corp. (<http:/ / www.dmed.co.jp/>) for editing a draft of this manuscript.

Conflicts of Interest: The authors declare no conflict of interest.

\section{References}

1. Collins, L.G.; Swartz, K. Caregiver care. Am. Fam. Physician 2011, 83, 1309-1317. [PubMed]

2. Adelman, R.D.; Tmanova, L.L.; Delgado, D.; Dion, S.; Lachs, M.S. Caregiver burden: A clinical review. JAMA 2014, 311, 1052-1060. [CrossRef] [PubMed]

3. Schulz, R.; Czaja, S.J. Family Caregiving: A Vision for the Future. Am. J. Geriatr. Psychiatry Off. J. Am. Assoc. Geriatr. Psychiatry 2018, 26, 358-363. [CrossRef]

4. McKeown, L.P.; Porter-Armstrong, A.P.; Baxter, G.D. The needs and experiences of caregivers of individuals with multiple sclerosis: A systematic review. Clin. Rehabil. 2003, 17, 234-248. [CrossRef]

5. Oliveira, D.; Sousa, L.; Orrell, M. Improving health-promoting self-care in family carers of people with dementia: A review of interventions. Clin. Interv. Aging 2019, 14, 515-523. [CrossRef]

6. Centers for Disease Control and Prevention. Caregiving for Family and Friends-A Public Health Issue. Available online: https:/ / www.cdc.gov/aging/caregiving/caregiver-brief.html (accessed on 3 November 2020).

7. Krogsbøll, L.T.; Jørgensen, K.J.; Gøtzsche, P.C. General health checks in adults for reducing morbidity and mortality from disease. Cochrane Database Syst. Rev. 2019, 1, Cd009009. [CrossRef]

8. Lee, S.; Colditz, G.A.; Berkman, L.F.; Kawachi, I. Caregiving and risk of coronary heart disease in US women-A prospective study. Am. J. Prev. Med. 2003, 24, 113-119. [CrossRef]

9. Miyawaki, A.; Tomio, J.; Kobayashi, Y.; Takahashi, H.; Noguchi, H.; Tamiya, N. Impact of long-hours family caregiving on non-fatal coronary heart disease risk in middle-aged people: Results from a longitudinal nationwide survey in Japan. Geriatr. Gerontol. Int. 2017, 17, 2109-2115. [CrossRef]

10. OECD. Health Check-Ups in Japan. Available online: https://doi.org/10.1787/9789264311602-7-en (accessed on 2 August 2020).

11. Nakanishi, N.; Tatara, K.; Tatatorige, T.; Murakami, S.; Shinsho, F. Effects of preventive health services on survival of the elderly living in a community in Osaka, Japan. J. Epidemiol. Community Health 1997, 51, 199-204. [CrossRef] 
12. Khan, M.M.; Goto, R.; Sonoda, T.; Sakauchi, F.; Washio, M.; Kobayashi, K.; Mori, M. Impact of health education and screening over all-cause mortality in Japan: Evidence from a cohort study during 1984-2002. Prev. Med. 2004, 38, 786-792. [CrossRef]

13. Torimoto-Sasai, Y.; Igarashi, A.; Wada, T.; Ogata, Y.; Yamamoto-Mitani, N. Female family caregivers face a higher risk of hypertension and lowered estimated glomerular filtration rates: A cross-sectional, comparative study. BMC Public Health 2015, 15, 177. [CrossRef]

14. Sugiyama, T.; Tamiya, N.; Watanabe, T.; Wakui, T.; Shibayama, T.; Moriyama, Y.; Yamaoka, Y.; Noguchi, H. Association of care recipients' care-need level with family caregiver participation in health check-ups in Japan. Geriatr. Gerontol. Int. 2018, 18, 26-32. [CrossRef]

15. Wills, T.A.; Ainette, M.C. Social networks and social support. In Handbook of Health Psychology, 2nd ed.; Baum, A., Revenson, T.A., Singer, J., Eds.; Psychology Press: New York, NY, USA, 2012; pp. 465-492.

16. Messina, C.R.; Lane, D.S.; Glanz, K.; West, D.S.; Taylor, V.; Frishman, W.; Powell, L. Relationship of social support and social burden to repeated breast cancer screening in the women's health initiative. Health Psychol. 2004, 23, 582-594. [CrossRef]

17. Silva, I.T.E.; Griep, R.H.; Rotenberg, L. Social support and cervical and breast cancer screening practices among nurses. Rev. Lat. Am. Enferm. 2009, 17, 514-521. [CrossRef]

18. Documet, P.; Bear, T.M.; Flatt, J.D.; Macia, L.; Trauth, J.; Ricci, E.M. The Association of Social Support and Education with Breast and Cervical Cancer Screening. Health Educ. Behav. 2015, 42, 55-64. [CrossRef]

19. Holt-Lunstad, J.; Uchino, B.N. Social Support and Health. In Health Behavior: Theory, Research, and Practice, 5th ed.; Glanz, K., Rimer, B.K., Viswanath, K., Eds.; Jossey-Bass: San Francisco, CA, USA, 2015; pp. 183-204.

20. Williams, S.W.; Dilworth-Anderson, P. Systems of social support in families who care for dependent African American elders. Gerontologist 2002, 42, 224-236. [CrossRef]

21. Shiba, K.; Kondo, N.; Kondo, K. Informal and Formal Social Support and Caregiver Burden: The AGES Caregiver Survey. J. Epidemiol. 2016, 26, 622-628. [CrossRef]

22. Kuluski, K.; Nelson, M.L.A.; Tracy, C.S.; Alloway, C.A.; Shorrock, C.; Shearkhani, S.; Upshur, R.E.G. Experience of Care as a Critical Component of Health System Performance Measurement: Recommendations for Moving Forward. HealthcarePapers 2017, 17, 8-20. [CrossRef]

23. Rose, J.H.; Bowman, K.F.; O’Toole, E.E.; Abbott, K.; Love, T.E.; Thomas, C.; Dawson, N.V. Caregiver objective burden and assessments of patient-centered, family-focused care for frail elderly veterans. Gerontologist 2007, 47, 21-33. [CrossRef]

24. Nakayama, G.; Masumoto, S.; Haruta, J.; Maeno, T. Measuring family caregivers' experience of interprofessional care for patients and families: Development of the Japanese version of the Caregivers' Experience Instrument. Fam. Pract. 2020, 37, 854-861. [CrossRef]

25. Guilabert, M.; Amil, P.; Gonzalez-Mestre, A.; Gil-Sanchez, E.; Vila, A.; Contel, J.C.; Ansotegui, J.C.; Solas, O.; Bacigalupe, M.T.; Fernandez-Cano, P.; et al. The Measure of the Family Caregivers' Experience. Int. J. Environ. Res. Public Health 2018, 15. [CrossRef]

26. Anhang Price, R.; Elliott, M.N.; Zaslavsky, A.M.; Hays, R.D.; Lehrman, W.G.; Rybowski, L.; Edgman-Levitan, S.; Cleary, P.D. Examining the role of patient experience surveys in measuring health care quality. Med. Care Res. Rev. MCRR 2014, 71, 522-554. [CrossRef]

27. World Health Organization. Innovative Care for Chronic Conditions: Building Blocks for Actions: Global Report 2002. Available online: https: / /apps.who.int/iris/handle/10665/42500 (accessed on 2 August 2020).

28. American Academy of Family Physicians. Definition of Family 1984. Available online: https://www.aafp.org/about/policies/ all/family-definition.html (accessed on 2 August 2020).

29. Ministry of Health, Labour and Welfare. Comprehensive Survey of Living Conditions: Health of Household Members. 2016. Available online: https:/ / www.mhlw.go.jp/toukei/chousahyo/koku28ke.pdf (accessed on 2 August 2020).

30. Mira, J.J.; Nuno-Solinis, R.; Guilabert-Mora, M.; Solas-Gaspar, O.; Fernandez-Cano, P.; Gonzalez-Mestre, M.A.; Contel, J.C.; Del Rio-Camara, M. Development and Validation of an Instrument for Assessing Patient Experience of Chronic Illness Care. Int. J. Integr. Care 2016, 16, 13. [CrossRef]

31. Miyawaki, A.; Tanaka, H.; Kobayashi, Y.; Kawachi, I. Informal caregiving and mortality-Who is protected and who is not? A prospective cohort study from Japan. Soc. Sci. Med. 2019, 223, 24-30. [CrossRef]

32. Arai, Y.; Tamiya, N.; Yano, E. The short version of the Japanese version of the Zarit Caregiver Burden Interview (J-ZBI_8): Its reliability and validity. Nihon Ronen Igakkai Zasshi Jpn. J. Geriatr. 2003, 40, 497-503. [CrossRef]

33. Arai, Y.; Zarit, S.H. Determining a cutoff score of caregiver burden for predicting depression among family caregivers in a large population-based sample. Int. J. Geriatr. Psychiatry 2014, 29, 1313-1315. [CrossRef]

34. Ministry of Health, Labour and Welfare. Long-Term Care Insurance System of Japan 2016. Available online: https://www.mhlw. go.jp/english/policy / care-welfare/care-welfare-elderly/dl/ltcisj_e.pdf (accessed on 3 November 2020).

35. Peduzzi, P.; Concato, J.; Kemper, E.; Holford, T.R.; Feinstein, A.R. A simulation study of the number of events per variable in logistic regression analysis. J. Clin. Epidemiol. 1996, 49, 1373-1379. [CrossRef]

36. Tang, Y.Y.; Chen, S.P. Health promotion behaviors in Chinese family caregivers of patients with stroke. Health Promot. Int. 2002, 17, 329-339. [CrossRef]

37. McDaniel, S.H.; Campbell, T.L.; Hepworth, J.; Lorenz, A. Family-Oriented Primary Care, 2nd ed.; Springer: New York, NY, USA, 2005; pp. 242-260. 
38. Aoki, T.; Inoue, M. Primary care patient experience and cancer screening uptake among women: An exploratory cross-sectional study in a Japanese population. Asia Pac. Fam. Med. 2017, 16, 3. [CrossRef]

39. Flocke, S.A.; Stange, K.C.; Zyzanski, S.J. The association of attributes of primary care with the delivery of clinical preventive services. Med. Care 1998, 36, AS21-AS30. [CrossRef]

40. Van Stralen, K.J.; Dekker, F.W.; Zoccali, C.; Jager, K.J. Confounding. Nephron Clin. Pract. 2010, 116, c143-c147. [CrossRef] 